\title{
Pain Coping Strategies with Functional Disability and Quality Of Life in Patients with Knee Osteoarthritis in Lagos, Nigeria
}

\author{
*AIYEGBUSI, AI; ISHOLA, T; AKINBO, SRA
}

\author{
Department of Physiotherapy, College of Medicine, University of Lagos, Nigeria, PMB 12003, Idiaraba, Lagos, Nigeria. 02341 \\ *Corresponding Author Email: aaiyegbusi@unilag.edu.ng, Tel: +2348023212513
}

\begin{abstract}
The significant impact of coping strategies on the experience of pain and disease outcome has been associated with cultural and environmental factors. There is a dearth of studies in this environment on the association of coping strategies with clinical symptoms in patients with OA knee. This study investigated the relationship among pain coping strategy, functional disability, pain and quality of life among patients with knee osteoarthritis in Lagos, Nigeria. Involved were 102 participants diagnosed with either bilateral or unilateral Knee OA. Numerical pain rating scale (NPRS), The Western Ontario and McMaster Universities Osteoarthritis Index (WOMAC osteoarthritis index), Pain coping inventory (PCI) and SF-36 Health survey were used to evaluate participants' pain, functional disability, pain coping strategy and quality of life $(\mathrm{QoL})$ respectively. Results showed a passive pain coping index (PPCI) score of $45.89 \pm 6.49$ as against $26.5 \pm 43.61$ for the active pain coping index (APCI). PPC strategies were significantly related positively with pain and functional disability $(\mathrm{p}<0.001 ; \mathrm{r}=0.380$ and $\mathrm{p}=0.001 ; \mathrm{r}=0.334$ respectively) but correlated negatively $(\mathrm{p}<0.001)$ with all domains of QoL except for mental health. On the other hand, APC strategies correlated negatively with pain and functional disability $(\mathrm{p}=0.092 ; \mathrm{r}=-0.168$ and $\mathrm{p}=0.334 ; \mathrm{r}=-0.131)$. Our findings thus suggest a significant association between PPCS and severe pain, functional disability and poor QoL while APCS was associated with a better quality of life in patients with knee OA. It is thus suggested that active pain coping strategies be incorporated into the management of patients with OA knee.
\end{abstract}

\section{DOI: https://dx.doi.org/10.4314/jasem.v22i12.10}

Copyright: Copyright $@ 2018$ Aiyegbusi et al. This is an open access article distributed under the Creative Commons Attribution License (CCL), which permits unrestricted use, distribution, and reproduction in any medium, provided the original work is properly cited.

Dates: Received: 30 November 2018; Revised: 20 December 2018; Accepted 24 December 2018

Keywords: Pain coping strategy, Knee osteoarthritis, Pain coping index, Numerical pain rating scale.

Osteoarthritis (OA) also known as degenerative arthritis is a chronic localized joint disease caused by the breakdown and eventual loss of the cartilage of one or more joints (Bhatia et al, 2013). Osteoarthritis interferes with many domains of an individual's wellbeing, therefore, approaches to OA treatment are mostly multimodal, with increasing focus on pain coping strategies adapted to individual patients (Allegrante and Marks, 2003). Coping is regarded as both conscious and unconscious efforts made by individuals to manage stress and negative feelings that are perceived as a drain on one's resources (Franco et $a l, 2004)$. Pain coping is the term used to describe a variety of ways to deal with or to overcome pain. Cognitive and behavioral reactions to chronic pain, commonly referred to as pain coping strategies may affect pain severity, functional capacity, and psychological functioning in participants with OA (Perrot et al, 2008) Coping strategies may be adaptive in the short-term but have been shown to be maladaptive in the longer term if pain becomes chronic (Hasenbring and Verbunt, 2010). Pain coping can be divided into active strategies where pain is overcome, handled, and taken control of and passive strategies which include withdrawal, avoidance, and negative self-confidence (McKnight et al, 2010). Active coping refers to those coping strategies that involve taking responsibility for pain management and include attempts to control pain or to function in spite of the pain while passive coping refers to strategies that involve giving responsibility for pain management to an outside source or allowing other areas of life to be adversely affected by pain. It has been shown also that participants using passive coping strategies have higher levels of pain and disability (Carroll et al, 2002). Perrot et al, (2008) reported that patients with knee OA use as much active as passive coping strategies with resting and reducing demands being the most used strategies. It has also been shown that the use of passive pain coping strategies increased with $\mathrm{OA}$ duration and was greater in older and overweight participants (Perrot et al, 2008). The physical manifestations of OA have direct impact on other aspects of patient's life such as social interactions, mental functioning and sleep quality (Ferrell, 1991). Therefore, the coping strategies people inherently use may have the potential to affect the outcome of their condition (Olarogba et al, 2014). Some prior cross-sectional studies have demonstrated an association between coping strategies and pain and 
disability (Somers et al, 2009). There also have been prior studies that identified the effect of cultural influences on pain coping with some cultures promoting a positive acceptance of pain as an inevitable and meaningful quality of ageing rather than a problem to be solved (Incayawar and Saucier, 2010). There is a dearth of study in this clime on the response of patients with OA to chronic pain (Thivian et al, 2014). The purpose of this study therefore was to determine the relationship of pain, functional disability and quality of life with pain coping strategies in participants with knee osteoarthritis in Lagos, Nigeria.

\section{MATERIALS AND METHODS}

Participants' selection: The study involved 102 participants who had been diagnosed with either bilateral or unilateral Knee Osteoarthritis. They were recruited from the physiotherapy outpatient clinics of two tertiary hospitals and a General Hospital. The participants were assessed by obtaining a detailed history and by carrying out physical examinations and radiographic assessment. Information relating to age, sex, duration of knee pain and past and present medications were collected from the patients Excluded from the study were participants with neurological disorders (such as Multiple sclerosis, dystonia, meningitis) and those with previous knee surgery. Also excluded were those with underlying systemic diseases, previous knee injuries, other rheumatic conditions of the knee and patients with severe OA using the Kellgren and Lawrence System of classification (1957).This to avoid the comorbidities presenting as confounding factors which may affect the results. Ethical approval was sought and obtained from the institutional Health Research and Ethics Committees prior to the commencement of the study with assigned approval numbers ADM/DCST/HREC/APP/766 and LSHSC/2222/VOL.XV/123. Informed consent was sought and obtained from each of the participants prior to commencement of the study and only those who gave their consent participated in the study.

Sample Size Calculation: The total number of participants for this study was calculated to be 78 based on a study by Murphy et al. (2012).

Description of instruments: Numerical Pain Rating Scale (NPRS): The numerical pain rating scale is a one-dimensional measure of pain intensity in adults (Childs, 2005). The most commonly used is the 11item NPRS point numerical scale which ranges from ' 0 ' representing "no pain" to ' 10 ' representing the "worst pain imaginable" (Hawker, 2011). Scores range from 0-10 points with higher scores indicating greater pain intensity (Hawker, 2011). The reliability and validity is of the NPRS is 0.95 (Ferraz et al, 1990).

Pain Coping Inventory (PCI): The PCI designed by Kraaimaat and Evers (2003) contains 33 claims which can be pooled into two major dimensions of cognitive and behavioral strategies for dealing with chronic pain. These include active pain coping dimensions with a maximum of 48 points (pain transformation, distraction, reducing demands) and passive paincoping dimensions with a maximum of 84 points (retreating, worrying and resting). The frequency with each claim, when feeling pain, is marked on a 4-point Likert scale ranging from 1 (hardly ever) to 4 (very often). The Cronbach's alpha coefficient for each domain of the PCI was $>0.68$ (Escobar et al, 2007).

WOMAC Osteoarthritis Index: The WOMAC osteoarthritis index is used to measure pain, stiffness and physical function. WOMAC scores were recorded on a Likert scale of 0-4 where $0=$ no pain/limitation; $1=$ mild pain/limitation; $2=$ moderate pain/limitation; $3=$ severe pain/limitation; and $4=$ very severe pain/limitation. The final score for the WOMAC is determined by adding the aggregate scores for pain, stiffness, and function. The data is standardized to a range of values from 0 to 100 , where 0 represents the best health status and 100 the worst possible status. An improvement is achieved by reducing the overall score (American College of Rheumatology, 2012). All WOMAC scales have been found to be internally consistent with Cronbach's alpha coefficients of 0.83 , 0.87, and 0.96 (Roos et al, 1999).

SF-36 Health Survey: The Short Form-36 derived from the General Health Survey of the Medical Outcomes Study by Stewart and colleagues (1988) is one of the most widely used generic measures of health-related quality of life. There is no single overall score for the SF-36, rather, it generates eight subscales and two summary scores. The 8 subscales are: physical functioning, role limitations due to physical problems, bodily pain, general health perceptions, vitality, social functioning, role-limitations due to emotional problems, and mental health. The two summary scores are the physical component summary and the mental component summary. Scores in each category range from 0 to 100 and higher scores indicates a better QoL (Kocyigit et al, 1999). The concurrent validity scores for scales and domains in the Yoruba version range between 0.749 and 0.902 (Mbada et al, 2015).

Participants' Preparation: A letter stating the purpose of the study, assuring participants of confidentiality and seeking informed consent was distributed with each copy of the outcome measure. The aim and 
objectives of the study was carefully explained to all participants as they were screened for exclusion with a set of questions that matched the criteria stated. The participants were given adequate information on how the procedures will be carried out and their sociodemographic information obtained. Copies of the outcome measure was administered to willing participants that satisfied the criteria for the study and completed copies of the outcome measure were retrieved.

Data Analysis: The data collected was analyzed using Statistical Package for Social Sciences (SPSS), version 20. Descriptive statistics of mean, frequency, standard deviation, charts and percentages, pie chart, bar chart and histogram was used to summarize the variables. Pearson's product moment correlation coefficient $r$ was used to determine the relationship between pain coping strategies and pain level, functional disability and quality of life of the participants. The level of significance was set at $\mathrm{p} \leq 0.05$

\section{RESULTS AND DISCUSSIONS}

One hundred and two participants $(10.8 \%$ males and $89.2 \%$ females) with a mean age of $60.8 \pm 4.7$ years were involved in the study. The majority of the participants presented with bilateral affectation $(69.6 \%)$ and there were more of the right knee affectation $(61.3 \%)$.

The mean value of pain on the NRS scale was $5.5 \pm 1.3$ with majority of the participants $(42 \%)$ having a pain score of 5.00 while only one $(1 \%)$ had a pain score of 10 . The results of the pain coping inventory (PCI), WOMAC and QoL are presented in table 1 while the correlations between pain coping strategies and the outcome parametres are shown on table 2 .

Table 1: Overall Scores of Active and Passive Pain Coping Dimensions and the Outcome Parametres

\begin{tabular}{l|llll}
\hline Outcome Parameters & Mean & SD & Minimum & Maximum \\
\hline Active PCI Subscale & 26.54 & 3.61 & 17 & 35 \\
Pain transformation & 8.77 & 1.97 & 4 & 15 \\
Distraction & 11.67 & 1.92 & 5 & 16 \\
Reducing demands & 2.02 & 2.16 & 3 & 12 \\
\hline Passive PCI Subscale & 45.89 & 6.49 & 28 & 63 \\
Retreating & 14.56 & 2.66 & 8 & 22 \\
Worrying & 18.01 & 3.32 & 10 & 28 \\
Resting & 13.41 & 2.41 & 7 & 20 \\
\hline WOMAC & & & & \\
Pain & 7.56 & 2.82 & 2 & 14 \\
Stiffness & 2.70 & 2.01 & 0 & 12 \\
Function & 24.54 & 7.94 & 9 & 45 \\
WOMAC Total & 34.74 & 10.80 & 12 & 61 \\
\hline NPRS & & & & \\
Pain & $5.5 \pm 1.3$ & 1.57 & 3 & 10 \\
\hline SF-36 & & & & \\
Physical Function & 45.49 & 20.37 & 10 & 100 \\
Vitality & 62.65 & 15,82 & 20 & 100 \\
Bodily Pain & 53.60 & 20.10 & 10 & 100 \\
General Health & 67.66 & 17.81 & 25 & 100 \\
Role Physical & 41.67 & 43.42 & 0 & 100 \\
Role Emotional & 62.75 & 46.51 & 0 & 100 \\
Social Functioning & 64.14 & 29.36 & 0 & 100 \\
Mental Health & 77.50 & 15.56 & 40 & 100 \\
\hline Cop & Men &
\end{tabular}

KEYS: PCI= Pain Coping Inventory; WOMAC= Western Ontario; McMaster University Index. SF $-36=$ Short form 36

Table 2: Correlation between Pain Coping Strategies and Pain Level, Functional Disability and Overall Scores of Quality of Life

\begin{tabular}{lll|lllll|lll}
\hline & Pain & \multicolumn{1}{c}{ WOMAC } & \multicolumn{2}{c}{ Physical Health Status } & \multicolumn{4}{c}{ Mental Health Status } \\
\hline & & & PF & RP & BP & GH & VT & SF & RE & MH \\
Active PCSr & -0.168 & -0.132 & -0.007 & 0.056 & 0.159 & 0.154 & 0.334 & 0.148 & 0.005 & 0.208 \\
$p$-value & 0.092 & 0.188 & 0.944 & 0.577 & 0.111 & 0.123 & $0.001^{*}$ & 0.137 & 0.961 & $0.036^{*}$ \\
\hline Passive PCSr & 0.380 & 0.334 & -0.404 & -0.424 & -0.446 & -0.486 & $0-.487$ & -0.410 & -0.351 & 0.331 \\
$p$-value & $0.000^{*}$ & $0.001^{*}$ & $0.000^{*}$ & $0.000^{*}$ & $0.000^{*}$ & $0.000^{*}$ & $0.000^{*}$ & $0.000^{*}$ & $0.000^{*}$ & $0.001^{*}$ \\
\hline
\end{tabular}

(* significant at $p \leq 0.05) ;$ KEYS; PCS= Pain Coping Strategies; WOMAC = Western Ontario McMaster University Index; SF-36= Short form 36; PF= Physical Functioning; RP=Role limitations due to Physical problem; BP=Bodily Pain; GH= General Health Perceptions; $V T=$ Vitality $; S F=$ Social Functioning; RE= Role limitations due to Emotional problems; MH= Mental Health

Osteoarthritis is unlike many other pain conditions in which the underlying injury typically resolves hence it is usually accompanied by chronic pain which leads to a decrease in physical function, disability, and poor quality of life (Perrot, 2008; Neogi and Zhang, 2013). Osteoarthritis interferes with many domains of health; 
therefore, treatment approaches are mostly multimodal, with increasing focus on pain coping strategies which is adapted to individual patients (Allegrante and Marks, 2003). This is because people with chronic conditions deal with stressors through active and passive coping strategies to adapt to the intensity of the pain and maintain their functioning and health (Liu et al, 2016). The participants in this study demonstrated lower active pain coping strategies (APCS) and much higher passive pain coping strategies (PPCS) as described by Kraaimaat and Evers (2003).The use of PPCS by these participants also resulted in higher functional disability as indicated by its significant positive correlation with the WOMAC scores; this was in line with prior studies on patients with OA knee and rheumatoid arthritis where passive coping was the primary psychological predictor of both pain and depression (Covic et al, 2000). These results suggest that the significant $(\mathrm{p}<0.001)$ positive correlation $(\mathrm{r}=0.038)$ between PPCS and pain may be responsible for the decrease in physical function and QoL of the participants in this study. In a prior study to determine the factors that significantly affected pain in RA patients, PPCS was discovered to have the strongest link, thus in line with a prior study, greater pain was detected with an increased use of passive coping (Brown and Nicassio, 1987). Consequently, an individual who experiences more pain will definitely exhibit more functional disability and a reduced QoL in line with a previous study that demonstrated a strong link between chronic pain and poor QoL (Lerman et al, 2015). In the evaluation of QoL, findings from this study showed that the domains related to the physical health status had relatively lower scores compared to the mental health component of the participants. This is consistent with findings from a study demonstrated by Zakaria et al (2009) who reported that higher scores in the mental component in patients with knee OA could be due to better coping mechanisms and adaptations to this chronic disease. This may suggests that patients that employ the use of PPCS have good mental health but generally have a poor quality of life as earlier reported (Tsonga et al, 2011). On the other hand, active coping which is defined as managing pain or trying to maintain function despite symptoms through the use of distraction and activity management resulted in better QOL and functional ability (Brown and Nicassio, 1987). There was a positive correlation between APCS and all the 8 domains of the sf-36 QoL though the only significant domains were the vitality and the mental health domains. Though PPCS is seen as maladaptive since patients lack control over the situation, there are indications however that passive coping strategies can be modified in individuals with chronic conditions resulting in improvements in health outcomes (Covic et al, 2000). Studies have shown that Individuals who develop more active coping styles are able to focus on the positive aspects of the situation, learn self-management skills, and thus able to successfully manage their symptoms (de Ridder et al, 2008). Though, the personality of an individual which is relatively fixed determines the way stressors are managed, the coping strategies adopted can however be taught and modified through modeling (Olle et al, 2009). Some other factors that could have affected the participants' mode of coping strategies are their sociodemographic factors such as the employment status, educational background and cultural factors. When compared with Caucasians, African Americans with $\mathrm{OA}$ and other chronic pain conditions report lower perceived ability to cope with and control pain and greater maladaptive coping strategies (Allen et al, 2012). Further studies are therefore needed to investigate the role of these confounding factors on the patients' dominant coping strategies. Clinicians managing patients with $\mathrm{OA}$ and those with other chronic diseases are therefore encouraged to help patients maximize their function and reduce symptoms by adopting an individualized approach to selfmanagement using more cognitive strategies. These patients should be advised to be more active as evidence indicates that people who experience chronic disease may be prone to inactivity and passive/avoidance behaviour despite the fact that these behaviour result in reduced functional ability (Jones et $a l, 2008)$. A limitation of this study was the relatively small sample size and the fact that it was a cross sectional study. Since the adaptive coping strategies may change during the course of disease, future longitudinal studies are recommended to better evaluate the responses of patients and determine which specific passive coping strategies are maladaptive (Arndt et al, 2010).

Conclusion: The results reported in this study suggest a significant association between PPCS and severe pain, functional disability and poor QoL while APCS was associated with a better quality of life in patients with knee OA. It is thus recommended that active pain coping strategies be incorporated into the management of patients with OA knee.

\section{REFERENCES}

Allegrante, JP; Marks, R. (2003). Self-efficacy in management of osteoarthritis. Rheumatic Diseases Clinics of North America. 29: 747-68.

Allen, KD; Bosworth, HB; Coffman, CJ; Lindquist, JH; Sperber, N; Weinberger, $M$ et al (2012). Racial differences in pain coping efficacy in patients with hip and knee osteoarthritis. Washington: Annual 
Meeting of the American College of Rheumatology

American College of Rheumatology (2012).Western Ontario and McMaster Universities Osteoarthritis Index (WOMAC)--General Description.

Arndt,B; Thomas Ostermann, Edmund, AM; Neugebauer; Peter Heusser (2010). Adaptive coping strategies in patients with chronic pain conditions and their interpretation of disease BMC Public Health. 10:507

Bhatia. D; Bejarano, T; Novo, M (2013). Current interventions in the management of knee osteoarthritis. Journal Pharmacy and Bioallied Sciences. 5(1): 30-38.

Brown, GK; Nicassio, PM. (1987).Development of a questionnaire for the assessment of active and passive coping strategies in chronic pain patients. Pain. 31:53-64

Carroll, L; Mercado, AC; Cassidy, JD; Cote, P (2002). A Population-based study of factors associated with combinations of active and passive coping with neck and low back pain. J. Rehab. Med. 34: 67-72.

Childs, JD; Piva, SR; Fritz, JM (2005). Responsiveness of the numeric pain rating scale in patients with low back pain. Spine 30: 1331-4.

Covic, T; Adamson, B; Hough, M (2000). The impact of passive coping on rheumatoid arthritis pain. Journal of Rheumatology 39(10): 27-30.

de Ridder, D; Geenen, R; Kuijer, R; van Middendorp, $\mathrm{H}$ (2008). Psychological adjustment to chronic disease. Lancet 37 (2): 246-55.

Escobar, A; Quintana, JM; Bilbao, A; Aróstegui, I; Lafuente, I; Vidaurreta, I (2007). Responsiveness and clinically important differences for the WOMAC and SF-36 after total knee replacement. Osteoarthritis Cartilage. 15 (3):273-80.

Ferrell, BA (1991). Pain management in elderly people. J. Amer. Geriatrics Soc. 39(1): 64-7.

Franco, RL; Garcia, CF; Picabia, BA (2004). Assessment of chronic pain coping strategies. Association of Salem Keizer Education Support Professionals 32(2): 82-91.
Hasenbring, MI; Verbunt, JA (2010). Fear-avoidance and endurance-related responses to pain: new models of behavior and their consequences for clinical practice. Clinic. J. Pain 26: 747-753.

Hawker, GA (2011) Measures of Adult Pain. Arthritis Care \& Research 63:S240-S252

Incayawar, M; Saucier, JF (2010). Pain in remote Andean communities - Learning from the Quicha (Inca) experience. Rural and Remote Health 10:1379

Jones, AC; Kwoh, CK, Groeneveld, PW; Mor, M; Geng, M; Ibrahim, SA (2008). Investigating racial differences in coping with chronic osteoarthritis pain. J Cross Cult Gerontol. 23:339-47.

Kellgren, JH; Lawrence, JS (1957). "Radiological assessment of osteo-arthrosis". Annals of the rheumatic diseases. 16 (4): 494-502.

Kocyigit, H; Aydemir, O; Fisek, G (1999). Form-36 (KF-36)'nin Turkce versiyonunun guvenilirligi ve gecerliligi. Ilac ve Tedavi Dergisi. 12:102-6.

Kraaimaat, FW; Evers, AW (2003). Pain-coping strategies in chronic pain patients: Psychometric characteristics of the pain-coping inventory (PCI). International J. Behave. Med.. 10(4): 343-63.

Lerman, SF; Rudich, Z; Brill, S; Shalev, H; Shahar, G (2015).Longitudinal associations between depression, anxiety, pain, and pain-related disability in chronic pain patients. Psychosom Med. 77(3):333-341.

Liu, R; Damman, W; Kaptein, AA; Rosendaal, FR; Kloppenburg, M. (2016). Coping styles and disability in patients with hand osteoarthritis. Rheumatology. 55: 4118.

Mbada, CE; Gafar, AA; Ogunlana, MO; Adedoyin, RA; Akinsulore, A; Awotidebe TO (2015). Translation, cross-cultural adaptation and psychometric evaluation of yoruba version of the short-form 36 health survey. Health Qual Life Outcomes. 13: 141.

McKnight, PE; Afram, A; Kashdan, TB; Kasle, S; Zautra, A (2010). Coping self-efficacy as a mediator between catastrophizing and physical functioning: treatment target selection in an osteoarthritis sample. J. Behave. Med. 33: 239.

Neogi, T; Zhang, Y (2013). Epidemiology of 
osteoarthritis. Rheumatic Disease Clinic North America 39(1): 1-19.

Olarogba, OB; Idowu, OA; Adegun, JA; Ajayi, VO (2014). Gender differences in pain perception and coping strategies among patients with knee and or hip osteoarthritis. Merit Res. J. Med. Medic. Sci. 2(7): 146-151

Olle, JZ; Sahler, J, Carr, E. (2009). Coping strategies In Developmental-Behavioral Pediatrics (fourth edition), pages 491-496. edited by:William B. Carey, MD, Allen C. Crocker, MD, William L. Coleman, MD, Ellen Roy Elias, MD, and Heidi M. Feldman, MD, PhD ISBN: 978-1-4160-3370-7. Copyright $\odot 2009$ Elsevier Inc. All rights reserve

Perrot, S; Poirraudeau, S; Kabir, M; Bertin, P; Sichere, P; Serrie, P; Rannou, F (2008). Active or passive pain coping strategies in hip and knee osteoarthritis. Arthritis Care Research 59(11): 1555-62.

Roos, EM; Klässbo, M; Lohmander, LS (1999). WOMAC Osteoarthritis Index: Reliability, validity, and responsiveness in patients with arthroscopically assessed osteoarthritis. Scandinavian J. Rheumatic. 28:4
Somers, TJ; Keefe, FJ; Pells, JJ; Dixon, KE; Waters, SJ; Riordan, PA (2009). Pain catastrophizing and pain-related fear in osteoarthritis patients: relationships to pain and disability. J. Pain Symptom Manage. 37: 863-872.

Stewart, AL; Hays, RD; Ware JE (1988). "The MOS Short-Form General Health Survey: Reliability and Validity in a Patient Population." Medical Care (26): 724-31.

Thivian, P; Hendrik, AZ; Blackbeard, D (2014). Chronic pain perception and cultural experience. Procedia - Soc. Behave. Sci. 113:151 - 160 18770428

Tsonga, T; Kapetanakis, S; Papadopoulos, C (2011). Evaluation of improvement in quality of life and physical activity after total knee arthroplasty in greek elderly women. Open Orthopaedics J. 5: 343-7.

Zakaria, ZF; Bakar, AA; Hassmoni, HM; Rani, FA; Kadir, SA (2009). Health-related quality of life in patients with knee osteoarthritis attending two primary care clinics in Malaysia: a cross-sectional study. Asia Pacific Family Medicine 8:10 